\title{
O FENÔMENO DA SEGUNDA RESIDÊNCIA: O CASO DO RIO GRANDE ENTRE OS ESTADOS DE SÃO PAULO E MINAS GERAIS
}

\author{
Sara Pugliesi Larrabure*
}

\section{RESUMO}

Este artigo aborda o fenômeno da segunda residência em uma localidade do interior do Brasil, composta por dezesseis municípios situados entre os estados de São Paulo e Minas Gerais, ao longo do rio Grande. Nessa região encontram-se seis usinas hidrelétricas cujas implantações, a partir da década de 60, resultaram na formação de represas, valorizando-a ainda mais como espaço de lazer e recreação. Esse estudo, além de localizar, qualificar e quantificar esse tipo de ocupação na região, mostra como a construção de segundas residências contribuiu e contribui para a produção do espaço, ocupando de forma distinta quase toda a margem do rio.

\section{PALAVRAS-CHAVE:}

Segunda residência. Lazer. Turismo. Produção do espaço.

\begin{abstract}
This article shows the phenomenon of second homes in a specific place, inside the brazilian territory, composing by sixteen cities located into the states of São Paulo and Minas Gerais, beyond the river called Grande. This region has six hydroelectrics plants, witch ones, with their constructions , since 1969, resulted the formation of lakes, getting up the valorization of the space, much more about leisure and relax times. This study, besides locates, qualify and quantify this kind of occupation in that place, shows how the construction of second homes, in fact, influences in the space's production, occupying in a distinct way almost in the totally perimeter of the river.
\end{abstract}

\section{KEY-WORDS:}

Second homes. Leisure. Tourism. Space production.

\section{Introdução}

A região estudada, caracterizada pela presença de represas formadas a partir do barramento do rio para a implantação de usinas hidrelétricas, apresenta uma forma de ocupação bastante distinta, uma vez que suas residências secundárias aparecem espalhadas linearmente pelas margens do rio Grande. Essa ocupação pode ser considerada como "subúrbios de veraneio", já que os proprietários são famílias provenientes de centros urbanos próximos, como Franca, Ribeirão Preto e Uberaba.

Este estudo tem como objetivo fazer um panorama desses subúrbios de veraneio na

região, sendo um ensaio para verificar e levantar questões acerca da influência do fenômeno da segunda residência no processo de organização do espaço regional.

A metodologia utilizada no trabalho centrou-se na busca de informações que gerassem tabelas e mapas de modo a facilitar a visualização do fenômeno, além de uma busca por bibliografia sobre o assunto e posterior análise dos dados obtidos, coletando informações em órgãos oficiais e não oficiais, além de entrevistas informais com turistas e moradores locais. 


\section{Conceituação de subúrbios de veraneio}

Subúrbio (palavra derivada do inglês suburb, que significa sub-cidade) é um termo empregado para designar as regiões ao redor das áreas centrais de um aglomerado urbano, seja ele um município, um distrito ou outra instância política qualquer.

Nos Estados Unidos, o termo é empregado para designar áreas ao redor das grandes cidades nas quais comumente vivem famílias de classe média e/ou alta, onde em geral os índices de qualidade de vida e segurança são maiores que os das áreas residenciais centrais, além de possuírem baixa densidade populacional, com habitações baseadas em tipologias arquitetônicas de baixo gabarito (normalmente casas unifamiliares ao invés de edifícios multifamiliares) e com baixo coeficiente de aproveitamento dos terrenos, com as edificações isoladas no meio dos grandes lotes.

Já nas grandes cidades da América Latina, emprega-se a palavra subúrbio também para se referir às áreas que não possuem todos os recursos / infraestrutura (energia elétrica, água encanada, esgoto, coleta de lixo, etc.) e equipamentos sociais (instituições culturais e de saúde) das regiões centrais, ou possuem em quantidade muito inferior. A palavra é então, associada às regiões periféricas (periferias) que possuem perfil de renda baixa.

Porém, existem regiões no Brasil que despertam o interesse de camadas ricas da população e se encontram em áreas periféricas, em processo semelhante ao dos subúrbios ricos norte-americanos, marcadas principalmente pela forte presença de condomínios fechados. Exemplos destas áreas periféricas ricas no Brasil são: a Barra da Tijuca e Jacarepaguá na cidade do Rio de Janeiro, e os condomínios da Serra da Cantareira e Alphaville na Grande São Paulo.

Porém, o que se discutirá aqui é como esse fenômeno acontece de forma diferenciada distante das grandes cidades brasileiras (São Paulo, Rio de Janeiro, Belo Horizonte, Porto Alegre, etc), onde também nota-se o aparecimento de núcleos de subúrbios, porém não mais de primeira residência, e sim de segunda residência.

As segundas residências são alojamentos turísticos particulares, utilizados temporariamente nos momentos de lazer, por pessoas que têm domicílio permanente em uma outra localidade (TULIK, p. 21). Essa modalidade de turismo é conhecida também como veranismo, um movimento de visitantes em busca de aproveitar praias, mar e rios. Caracterizam-se pela procura dos turistas (veranistas) em se hospedarem em residências particulares (próprias, de amigos, de parentes ou alugadas por temporadas) ao invés da estrutura hoteleira. Além disso, é um fenômeno periódico, isto é, as pessoas procuram geralmente os mesmos lugares durante as férias ou feriados prolongados.

Uma vez que essas áreas no interior do Brasil possuem características semelhantes aos que encontramos nos subúrbios (como a baixa densidade de ocupação, casas e condomínios de luxo e proprietários de classe média alta) e são utilizadas por turistas para fins recreativos, julgamos oportuno o emprego do termo "subúrbios de veraneio".

\section{Subúrbios de veraneio: reflexões a partir do caso do Rio Grande}

A região objeto desta pesquisa se encontra ao norte do estado de São Paulo e sul de Minas Gerais, ao longo do rio Grande, é costada pelo complexo da Serra da Canastra (cadeira montanhosa localizada no centro-sul do estado de Minas Gerais) e apresenta topografia bastante acidentada. Está a cerca de 350 quilômetros de distância da capital paulista, São Paulo e a 310 quilômetros da capital mineira, Belo Horizonte. A região compreende os seguintes municípios (figura 1):

- Estado de São Paulo: Aramina, Igarapava, Miguelópolis, Pedregulho e Rifaina.

- Estado de Minas Gerais: Água Comprida, Cássia, Claraval, Conquista, Delfinópolis, Delta, Ibiraci, Passos, Sacramento, São João Batista do Glória e Uberaba (Ponte Alta). 
Figura 1. Localização da Área de Estudo.

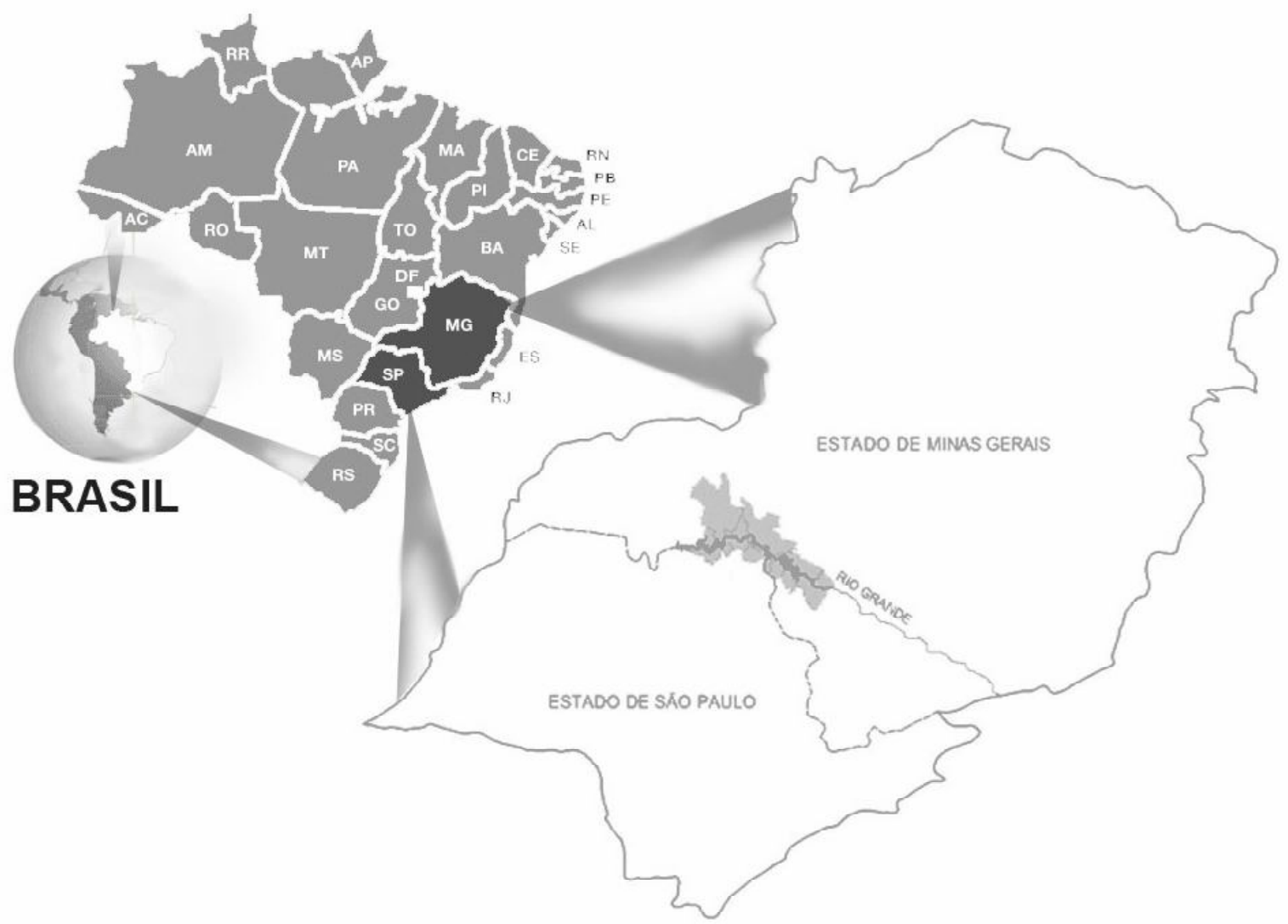

Fonte: autora, 2009.

O rio Grande tem sua nascente situada no estado de Minas Gerais, na Serra da Mantiqueira no município de Bocaina de Minas, e percorre 1.300 quilômetros até desembocar no rio Paranaíba, formando o rio Paraná. A partir do município de Claraval (MG), o rio forma a divisão política entre os estados de São Paulo e Minas Gerais.

\section{1 - Breve histórico}

O processo de ocupação desta região sofreu grande influência do crescimento populacional e do desenvolvimento econômico do estado de Goiás e do Sul de São Paulo, pois com a abertura de estradas em Goiás em 1722, começaram a surgir os primeiros povoados ao redor da rota dos bandeirantes paulistas em busca de minas de ouro.

Com a decadência do ouro em Minas Gerais muitos extrativistas da Serra da Mantiqueira passaram a se dirigir para as regiões norte e nordeste do Estado de São Paulo, buscando novas riquezas. Mais tarde, começam a surgir os primeiros imigrantes (italianos, portugueses e espanhóis) ligados à construção da estrada ferroviária que ligou o Norte do Brasil ao Centro do Estado de São Paulo, chamada linha 
"Rio Grande" (lado paulista) e "Linha Catalão" (lado mineiro), inaugurada no ano de 1886 pela Companhia Mogiana de Estradas de Ferro. Nos anos seguintes, a linha sofreu grandes alterações de rotas e em 1980 o complexo ferroviário foi desativado na região (ESTAÇÕES FERROVIÁRIAS DO BRASIL, 2009).

No final da década de 50 e início dos anos 60, a Companhia Energética de Minas Gerais (CEMIG) e Furnas Centrais Elétricas S.A., visando aproveitar o potencial energético do rio Grande, começaram a construção de seis usinas hidrelétricas, totalizando cerca de 620 quilômetros quadrados de áreas inundadas (CEMIG, 2006 e FURNAS, 2006). São elas:

\section{CEMIG :}

- Usina Hidrelétrica de Volta Grande Miguelópolis (SP), início de operações em 1974;

- Usina Hidrelétrica de Igarapava - Igarapava (SP), início de operações em 1999;

- Usina Hidrelétrica Jaguara - Rifaina (SP), início de operações em 1971.

Furnas:
- Usina Hidrelétrica Mascarenhas de Moraes/ Peixoto - Ibiraci (MG), operando desde 1957;

- Usina Hidrelétrica de Furnas - entre os municípios de São José da Barra e São João Batista do Glória (MG), operando desde 1963, mas com configuração atual de 1970;

- Usina Hidrelétrica Luiz Carlos Barreto de Carvalho/Estreito - Pedregulho (SP), operando desde 1969.

\section{2 - Expressividade do fenômendo de segunda residência}

De acordo com os dados do Instituto Brasileiro de Geografia e Estatística - IBGE (2000), a região conta com 7.027 residências secundárias, correspondendo a $7,91 \%$ do número total de residências dos municípios. Apesar da porcentagem ser baixa comparando-se com cidades litorâneas do sul e sudeste brasileiro, esse fenômeno é expressivo no contexto regional, uma vez que grande parte das residências secundárias se encontra às margens do rio.

Tabela 1: Proporção e Progressão de Domicílios de Uso Ocasional dos municípios estudados.

\begin{tabular}{|l|l|l|l|}
\hline \multirow{2}{*}{$\begin{array}{l}\text { Estado } \\
\text { situação do domicílio }\end{array}$} & \multicolumn{3}{|l|}{$\begin{array}{l}\text { Residências de Uso Ocasional em } \\
\text { Relação ao Total de Residências }\end{array}$} \\
\cline { 2 - 5 } & 1980 & 1990 & 2000 \\
\hline
\end{tabular}

\begin{tabular}{|l|l|l|l|}
\hline $\begin{array}{l}\text { Progressão de Crescimento de } \\
\text { Domicílios de Uso Ocasionais }\end{array}$ \\
\hline 1980 a 1990 & $\begin{array}{lll}1990 \\
2000\end{array}$ & a & 1980 a 2000 \\
\hline
\end{tabular}

\begin{tabular}{|l|l|l|l|}
\hline Municípios Sã o Paulo & $\mathbf{3 , 8 2} \%$ & $\mathbf{5 , 0 2} \%$ & $\mathbf{7 , 8 2} \%$ \\
\hline Urbana & $1,22 \%$ & $1,99 \%$ & $3,57 \%$ \\
\hline Rural & $7,88 \%$ & $13,17 \%$ & $25,77 \%$ \\
\hline
\end{tabular}

\begin{tabular}{|l|l|l|}
\hline $\mathbf{3 1 , 3 9} \%$ & $\mathbf{5 5 , 7 2} \%$ & $\mathbf{1 0 4 , 6 0} \%$ \\
\hline $62,94 \%$ & $79,77 \%$ & $192,92 \%$ \\
\hline $67,10 \%$ & $95,63 \%$ & $226,90 \%$ \\
\hline
\end{tabular}

\begin{tabular}{|l|l|l|l|}
\hline Municípios Minas Gerais & $\mathbf{1 , 8 8} \%$ & $\mathbf{5 , 8 1} \%$ & $\mathbf{7 , 9 4 \%}$ \\
\hline Urbana & $0,64 \%$ & $2,40 \%$ & $2,86 \%$ \\
\hline Rural & $6,40 \%$ & $14,34 \%$ & $24,03 \%$ \\
\hline
\end{tabular}

\begin{tabular}{|l|l|l|}
\hline $\mathbf{2 0 8 , 7 6} \%$ & $\mathbf{3 6 , 6 7 \%}$ & $\mathbf{3 2 1 , 9 9 \%}$ \\
\hline $272,91 \%$ & $18,84 \%$ & $343,16 \%$ \\
\hline $124,01 \%$ & $67,58 \%$ & $275,40 \%$ \\
\hline
\end{tabular}

\begin{tabular}{|c|l|l|l|}
\hline TOTAL dos Municípios & $\mathbf{2 , 1 8} \%$ & $\mathbf{5 , 5 8} \%$ & $\mathbf{7 , 9 1 \%}$ \\
\hline Urbana & $0,72 \%$ & $2,28 \%$ & $3,06 \%$ \\
\hline Rural & $6,77 \%$ & $14,01 \%$ & $24,43 \%$ \\
\hline
\end{tabular}

\begin{tabular}{|l|l|l|}
\hline $\mathbf{1 5 6 , 2 0} \%$ & $\mathbf{4 1 , 6 2} \%$ & $\mathbf{2 6 2 , 8 4} \%$ \\
\hline $219,01 \%$ & $34,10 \%$ & $327,79 \%$ \\
\hline $107,08 \%$ & $74,31 \%$ & $260,95 \%$ \\
\hline
\end{tabular}

Fonte: IBGE 1980, 1990 e 2000 - organizado pela autora. 
Os dados do IBGE mostram um crescimento do número de segunda residência na região em 262,84\% de 1980 para 2000, como pode ser observado na tabela acima. Diante disso, consideramos relevante o estudo dessa temática na região, uma vez que ela sofreu grandes mudanças devido a esse crescimento acelerado.

Porém, não se pode esquecer que os dados obtidos no IBGE são informações globais do município, o que pode nos levar a erros numéricos, como é o caso do município de Uberaba, que possui aproximadamente 60 quilômetros de perímetro margeado pelo rio, onde podemos encontrar apenas 164 residências secundárias (levantamento autora), porém em todo seu território encontra-se 3.399 habitações de uso ocasional. Isso acontece porque Uberaba é um município com grande extensão territorial e seu núcleo urbano está a cerca de 30 quilômetros de distância do rio, e para este estudo, foram considerados apenas os dados que julgamos relevantes para o entendimento do fenômeno de segundas residências nos arredores do rio Grande, ou seja, apenas os dados do distrito de Ponte Alta.

Analisando os dados fornecidos pelo IBGE (Figuras 1 e 2), percebe-se que quase todos os municípios estudados possuem maior número de residências secundárias localizadas em zona rural. Sendo exceções, os municípios de Rifaina e Igarapava (ambos em São Paulo), provavelmente por possuírem seu núcleo urbano às margens do rio, e neste caso podemos considerar que sua totalidade (valores IBGE) tem o rio como seu atrativo principal.

Logo, essa informação pode nos levar a pensar que o fenômeno de segunda residência na região está associado à existência do rio e suas represas.

Figura 1: Quantidade de Residências de Uso ocasional dos municípios de Aramina (SP), Igarapava (SP), Miguelópolis (SP), Pedregulho (SP) e Rifaina (SP).

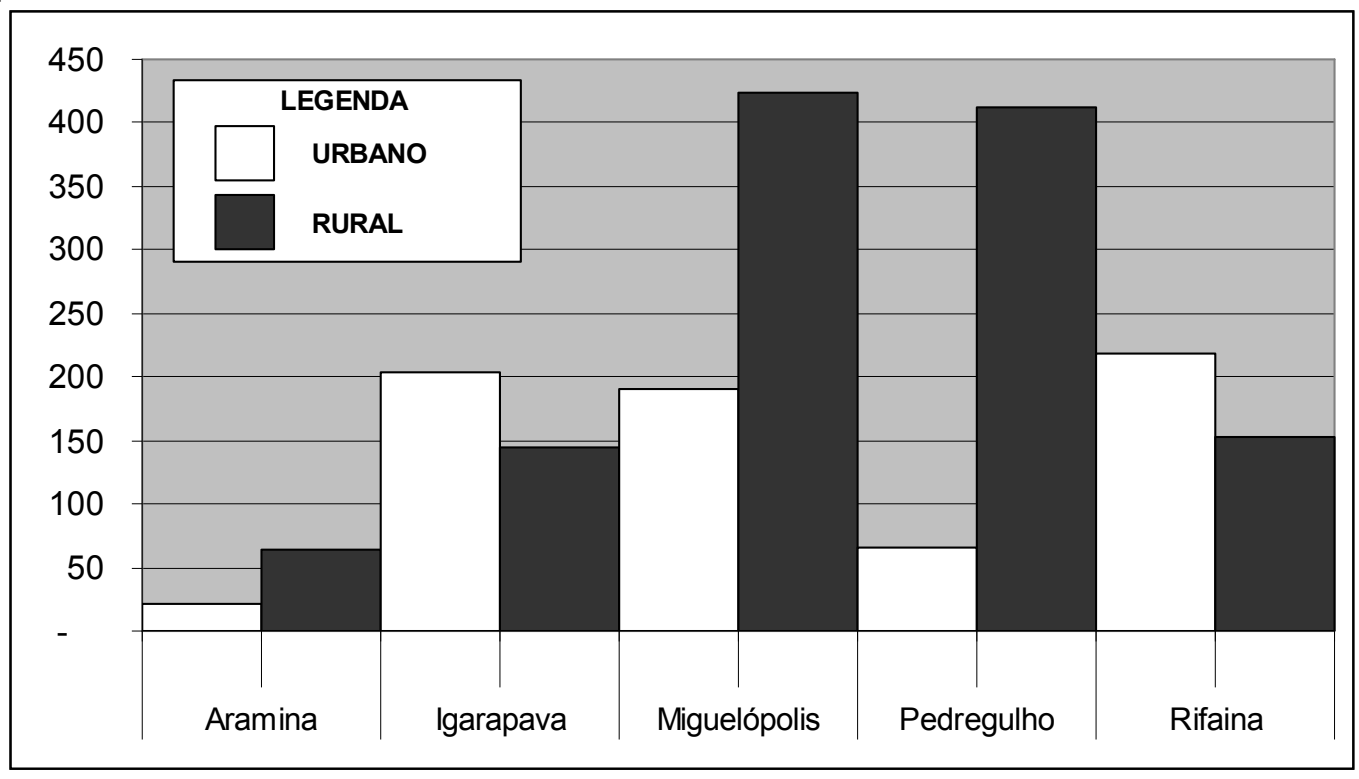

Fonte: IBGE 2000 - organizado pela autora. 
Figura 2: Quantidade de Residências de Uso ocasional dos municípios de Água Comprida (MG), Cássia (MG), Claraval (MG), Conquista (MG), Delfinopólis (MG), Ibaraci (MG), Passos (MG), Sacramento (MG), S.J.B.Glória (MG), Ponte Alta (MG).

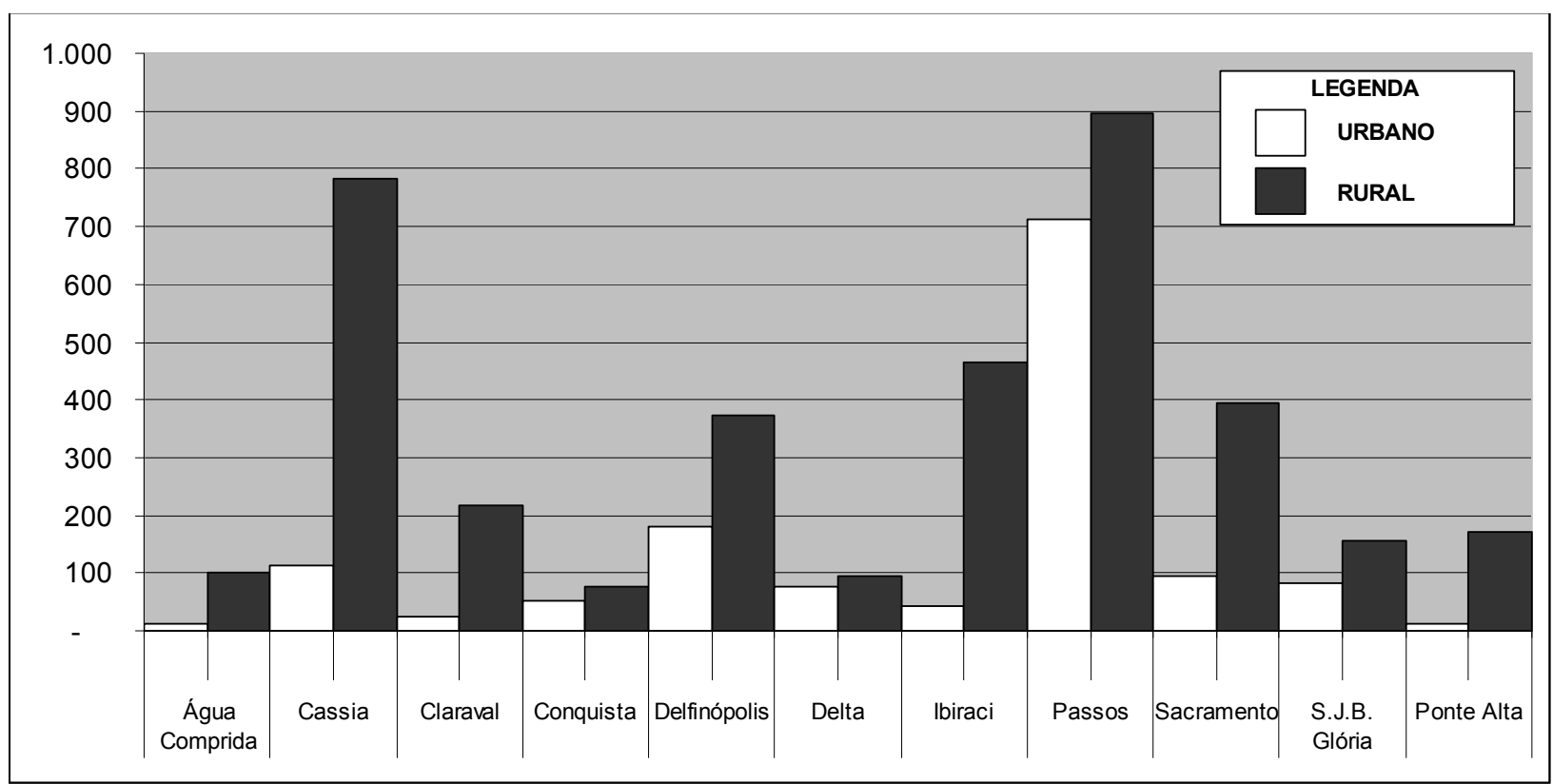

Fonte: IBGE 2000 - organizado pela autora.

\section{do espaço}

\section{A segunda residência e a produção}

Pelo fato da segunda residência ser uma das formas utilizadas pelo turismo para a apropriação do espaço, é necessário para a sua compreensão considerar a totalidade das relações em que se desenvolve a atividade.

"Apreender qual o papel que cabe ao turismo na produção do espaço e no ordenamento e reordenamento de territórios para seu uso requer a consideração de inúmeras variáveis que compõem o imenso jogo de relações do qual o turismo representa apenas uma parte" (CRUZ, 1999, p. 28).

Considerado como uma prática social e uma atividade econômica, o turismo tem o espaço como seu principal objeto de consumo, sendo que "nenhuma outra atividade consome, elementarmente, espaço" (CRUZ, 2001, p. 21).
Para Milton Santos espaço é "um conjunto indissociável, solidário e também contraditório, de sistemas de objetos e sistemas de ações, não considerados isoladamente, mas como o quadro único no qual a historia se dá" (SANTOS, 2004 , p. 63), ele é a matéria trabalhada, sendo o objeto social que mais tem domínio sobre o homem, estando presente no cotidiano das pessoas.

A produção do espaço resulta de processos políticos, sociais, econômicos e históricos, que funcionam como condições essenciais para produção e reprodução capitalista, de modo que o espaço é produzido e transformado segundo os interesses dos produtores.

Na região em questão, a produção do espaço teve como marco histórico a implantação das hidrelétricas. A região, já dotada de 
atrativos e particularidades (cachoeiras, vegetação exuberante, topografia acidentada e a presença do próprio rio), começou a despontar como local de descanso. Alguns empreendedores, percebendo essa valorização, aproveitaram e adquiriram terrenos beira-rio, onde aos poucos implantaram hotéis e pousadas. Concomitantemente, loteamentos foram sendo realizados e seus lotes vendidos às empresas e famílias da classe alta e, sobretudo, a famílias de classe média das cidades vizinhas, principalmente Franca, na época já um forte pólo industrial calçadista. Cidades como Ribeirão Preto e Uberaba também são pólos emissores significativos de turistas para a região.

Percebe-se que a iniciativa privada, com a venda de lotes à beira-rio, ajudou a impulsionar e fixar esse comércio do espaço. A população e o poder público, direcionados por essa iniciativa e seduzidos pela promessa de aumento na arrecadação de impostos e "desenvolvimento fácil", apostou e aposta todas as suas energias nesse novo negócio: o turismo.

Segundo Knafou (1996) é através da ação do mercado, e não mais a partir das práticas turísticas em si, que os espaços atualmente são turistificados. De acordo com as tendências e modismos, novos destinos e produtos turísticos são criados e disponibilizados à venda para o consumidor, numa relação estritamente econômica. Os especuladores imobiliários têm um papel importante na localização desses subúrbios de veraneio, aproveitando o marketing turístico para valorizar os atributos naturais e culturais de um determinado espaço.

O processo de apropriação do espaço pelo turismo é estabelecido a partir da ação dos diversos agentes do fenômeno (turistas, mercado, planejadores e promotores territoriais), que atuam de forma independente ou articulada, promovendo a reorganização do espaço em pelo menos três frentes: pólo emissor, espaços de deslocamento e pólos receptores de turistas, constituindo uma malha intrínseca da atividade turística que se reflete no ordenamento dos espaços apropriados.
As construções das barragens, aliadas à grande distância do litoral e ao grande número de pedágios existentes nas rodovias brasileiras, ajudaram a impulsionar o aparecimento de "subúrbios de veraneio", alterando significativamente a paisagem e modificando a vida cotidiana da população local. Essa área tornou-se conhecida na região, principalmente devido ao seu caráter elitista, criando a necessidade na parcela mais rica de possuir uma residência no local.

É nesse contexto que o turismo (incluindo, claro, os subúrbios de veraneio) se apresenta ao longo do rio Grande, pois ele está sujeito ao jogo de relações do capitalismo, fazendo com que cada vez mais os lugares sejam ocupados por objetos que são estranhos a eles, cujas lógicas são alheias e distantes do próprio lugar e de seus habitantes. Ele introduz o turista, que requer um sistema de objetos igualmente estranho ao lugar: hospedagem, estradas, infraestrutura de lazer, etc, além de apropriar-se de objetos préexistentes, que podem ganhar novas funções. Quando a atividade começa a se desenvolver, o turismo impõe a sua lógica e, muitas vezes, desconsidera o fato de esses lugares possuírem uma história e uma cultura. Esse processo provoca alterações significativas nas estruturas das populações residentes na área como: o abandono das atividades primárias (pesca, agricultura e pecuária), substituídas por aquelas do setor de prestação de serviços - como empresas que alugam equipamentos para a prática de esportes náuticos (jet ski, lanchas, etc.) ou que oferecem serviços de passeios ; a migração de trabalhadores de outras áreas; a construção de empreendimentos direcionados para as funções de lazer e recreação e o surgimento de restaurantes e bares que funcionam apenas nos finais de semana e dias de grande movimento. Nicolas (1996) diz que o processo de turistificação dos espaços implica a substituição da lógica da produção ("mundo do trabalho") pela lógica do ócio ("mundo do ócio"), e é justamente isso que se percebe na região. "A segunda residência converte o 'fim de
semana' em um fato sócio-cultural 
característico da sociedade contemporânea. A redução da jornada de trabalho, a degradação do meio urbano e o advento do automóvel particular contribuíram para a eclosão do fim de semana como o principal período de aproveitamento do tempo livre, sobretudo, via segunda residência" (QUEIROZ e SENA, 2006, p. 98).

As cidades tornaram-se vinculadas diretamente ao turismo, e se encontram dependentes desse fluxo sazonal. Algumas empresas turísticas, voltadas para o turismo da natureza e de esportes também começam a aparecer, em maior escala na cidade de Delfinópolis ( $M G)$, hoje já conhecida nacionalmente pela procura desses esportes (rafting, escalada).

A intenção de se possuir uma segunda residência está ligada à necessidade do gozo do tempo livre, sendo destinada para atividades de ócio, recreação e espairecimento. Para que isso seja possível, a renda é fator principal definidor de quem pode possuir, além do domicílio permanente (primeira residência), um outro destinado ao lazer de finais de semana e das temporadas de férias, implicando, portanto, a disponibilidade de uma renda excedente para a compra do terreno, construção e manutenção do imóvel e meio de transporte para o deslocamento. Esses fatores (tempo e renda) fazem da segunda residência uma modalidade de alojamento turístico elitista, símbolo de status social, característica principalmente encontrada na classe média. Ter uma segunda residência na região não significava apenas ter um lugar para descanso, mas se tornou também uma forma de demonstrar poder e posição social.

O fato das segundas residências serem usadas de forma descontínua, isto é, serem usadas principalmente aos finais de semana e férias, faz com que possuam um caráter temporal de ocupação, em contrapartida com a primeira residência ou residência permanente, englobando o tempo livre ou do não-trabalho.

"O uso pode ser repetido, mas não consecutivo por período superior a um ano, o que estabelece o vínculo territorial e um certo paralelismo com a definição aceita para turista, fato que reforça a noção de residência secundária como alojamento turístico" (TULIK, 1995, p. 21).

As populações temporais exigem a incorporação de suas implicações no planejamento das cidades onde se encontram, pois neste tipo de apropriação do espaço, o vínculo territorial é mais forte em razão de uma visitação frequente. SANCHEZ (1985, p. 11) relaciona residência secundária a um "turismo sedentário", observando que nessa modalidade de alojamento turístico, o uso repetido do mesmo espaço cria alguma forma de vínculo territorial e psicossociológico, estabelecendo uma ligação espacial restrita a períodos ocasionais menores ou semipermanentes e mais duradouros. A mobilização de capital em uma residência de uso esporádico motiva seus proprietários a seu uso regular, e isso quer dizer que, teoricamente, as residências secundárias tendem a ser mais expressivas como fenômeno espacial em localidades relativamente próximas de seus principais pólos emissores de turistas e que devem possuir facilidades de acesso, tais como estradas de boa qualidade.

Percebe-se então uma relação definida pelo tempo-custo-distância:

"(...) não se pode negligenciar o fato de que melhorias no setor de transportes (maior conforto e velocidade dos automóveis e modernização de vias de circulação) influem, diretamente, na possível ampliação da distância entre moradia e residência secundária, já que, nesse caso, a relativização do tempo é, também, relativização do espaço" (CRUZ, 2007, p. 59).

Por isso, a maior concentração de segundas residências acontece próximo à Rodovia Candido Portinari, que liga Ribeirão Preto a Uberaba, permitindo melhor fluidez das pessoas, fácil e rápido acesso, e, quanto mais nos afastamos desse eixo, mais rarefeitos são os condomínios.

As segundas residências "têm certa autonomia relativamente ao setor de operação e 
agenciamento de viagens, mas têm um forte vínculo com o mercado imobiliário que define, na grande parte das vezes, quais são e quais serão as áreas ocupadas por esses imóveis" (CRUZ, 2007, p. 62). Além disso, o relevo influi diretamente na escolha dessas áreas, pois, por ser uma região que apresenta topografia bastante acidentada, os lugares onde as margens da represa são íngremes dificultam sua ocupação, como é o caso da divisa entre os municípios de Ibiraci e Sacramento. Outro fator que influencia a não ocupação da margem do rio é a presença de uma barragem, uma vez que esses terrenos pertencem às companhias energéticas.

Como englobam e articulam diversas esferas da organização socioespacial, as residências secundárias requerem um maior número de estudos com o objetivo de analisar os efeitos positivos e negativos percebidos nos locais onde elas se encontram.

O turismo traz benefícios à população, pois gera empregos e quando localizado em áreas urbanas, contribui para a receita municipal. Porém, muitas vezes, aspectos negativos decorrem especialmente da especulação e exploração descompromissada do setor imobiliário e descaso por parte dos usuários do valor socioambiental da represa.

Já para SEABRA (1979), as segundas residências podem levar uma cidade a perder suas condições balneárias e a se transformar, por exemplo, em centro de comércio e de serviços, como aconteceu em Santos no litoral de São Paulo, objeto de sua análise. Outras repercussões negativas, segundo BARROS (1998, p. 28), dizem respeito ao fato de as segundas residências geralmente

"desalojarem com suas edificações e infraestruturas o uso do solo tradicional anterior, agrícola e pesqueiro e provocarem turbulência a níveis culturais e sociais (perfis de emprego, alterações de estilos e horizontes de vida, etc.) $e$ ambientais (desorganização da drenagem e mudanças geomorfológicas, destruição das qualidades das águas doces e oceânicas etc.)".
Essas alterações afetam o ordenamento dos espaços apropriados pelo turismo, podendo causar consequências bastante negativas como o crescimento urbano predatório, a eliminação das paisagens naturais e a geração de conflitos internos nos grupos sociais locais e nas suas relações com os visitantes e agentes do mercado turístico.

Outra característica marcante desse fenômeno é sua horizontalidade, já que sua ocupação segue um mesmo padrão em toda a sua extensão independente do município, criando-se aglomerados (em forma de manchas) que se espalham linearmente por todo o perímetro margeado pelo rio (ver figura $2)$. Os lotes são grandes, com construções horizontais (de um ou, raras vezes, dois pavimentos), recuadas entre si e com padrões comuns de ajardinamento.

Para MACEDO (1993, p. 46),

"esses padrões de urbanização são apontados como principais fatores de destruição dos recursos paisagísticos e ambientais existentes [...] têm muitas vezes totalmente eliminadas as características que geraram suas ocupações, com uma grande e definitiva perda de suas qualidades paisagísticas iniciais".

Além disso, é evidente a poluição das águas e do solo, a erradicação total ou parcial da mata nativa em alguns trechos, assoreamento do rio e exigência de carga econômica municipal para criação de infraestrutura para uma zona que só é ocupada durante poucas semanas do ano, o que o faz concluir que

"a ocupação de veraneio modifica a morfologia existente para adequá-la ao ideário urbano do bairro-jardim, onde o terreno é modelado e parcelado de modo a receber casas e lotes convencionais de dimensões maiores que os existentes dentro de uma malha urbana tradicional [...] na maior parte dos casos não existe o cuidado ou a consciência da adequação e do aproveitamento total ou parcial, dos valores paisagísticos e ambientais exigentes" (Macedo, 1998, p. 140). 
Figura 2: Mapeamento dos núcleos de "subúrbios de veraneio" e localização das usinas hidrelétricas na área estudada.

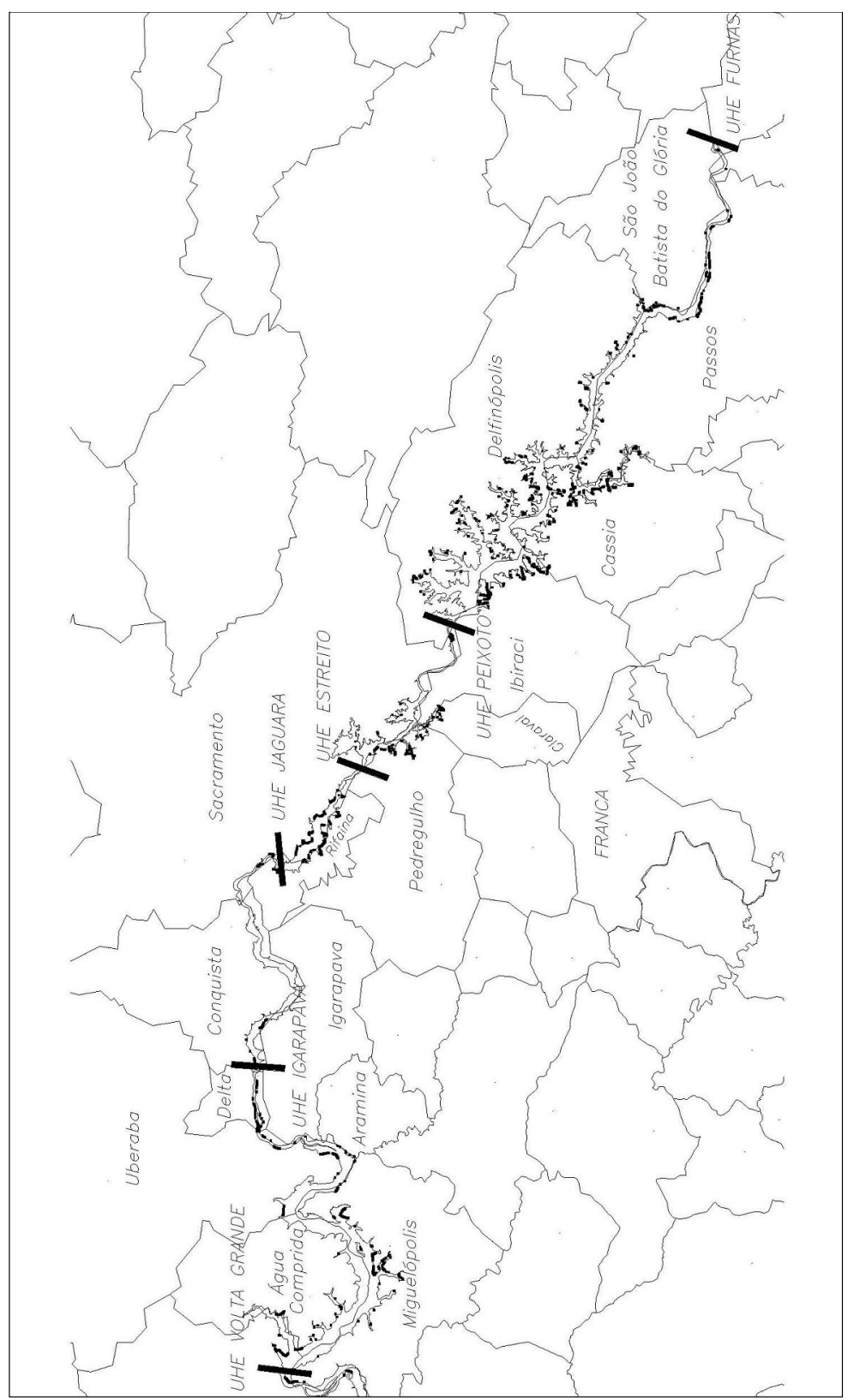

Fonte: autora, 2009. 
As residências esporádicas lineares em torno do rio vendidas até o final de 2000 estão dando espaço para conjuntos e condomínios, como visto no município de Rifaina. Os antigos alojamentos dos operários que trabalhavam na construção das usinas ganham novas funções, como é o caso do loteamento "Marina de Jaguara" às margens da represa de Jaguara em Sacramento, hoje sendo comercializada cada residência, com lotes variando entre $203 \mathrm{~m}^{2}$ a $700 \mathrm{~m}^{2}$, por volta de $\mathrm{R} \$ 150.000,00$.

Segundo o Código Florestal Brasileiro (Lei no 4.771/65), em seu artigo $2^{\circ}$, devem ser consideradas como Áreas de Preservação Permanente as áreas situadas ao longo dos rios ou de qualquer curso d'água com largura mínima de 30 (trinta) metros, chegando até 500 (quinhentos) metros, e ao redor das lagoas, lagos ou reservatórios d'água naturais ou artificiais. Após o levantamento realizado com base nas imagens de satélite, percebeu-se que a forma de ocupação vigente na região está em desacordo tanto com o artigo $2^{\circ}$ quanto com o $16^{\circ}$, que fala da obrigatoriedade de manter vinte por cento da vegetação natural em propriedade rurais localizada em qualquer região do País. $\mathrm{Na}$ realidade o que se vê são terrenos totalmente modificados, com alterações significativas no relevo, retirada da vegetação natural, instalação de cercas que adentram o rio delimitando a área do lote e criação de plataformas de atracamento.

Além disso, as residências secundárias localizadas nas áreas rurais na região não contam com abastecimento de água, coleta de esgoto ou recolhimento do lixo e, em grande parte, está com irregularidades junto à prefeitura (ausência de escritura, cadastramento e aprovações) e às concessionárias energéticas.

O Código Florestal, no artigo $22^{\circ}$, diz que é de competência da "União, diretamente, através do órgão executivo específico, ou em convênio com os Estados e Municípios, fiscalizar a aplicação das normas deste Código", e prevê no parágrafo único que "nas áreas urbanas [...] a fiscalização é da competência dos municípios, atuando a União supletivamente". Porém a Constituição Brasileira de 1988 prevê a descentralização política, fortalecendo a autonomia municipal e desfazendose o poder central de obrigações que lhe eram atribuídas. No artigo 30 do inciso II da Constituição fica claro que cabe ao município legislar em matéria de interesse local e suplementar a legislação estadual e federal, já no artigo 24 diz que cabe à União e aos Estados a competência para legislar sobre direitos urbanísticos e conservação da natureza, mas não cita os municípios. Além disso, a Lei Federal da Política Nacional do Meio Ambiente - PNMA ( $\mathrm{n}^{\circ}$ $6.938 / 81$ ) formulou o conceito do Sistema Nacional do Meio Ambiente, tendo como proposta a criação e implantação de uma política nos três níveis institucionais (federal, estadual e municipal). Como o Código Florestal e a PNMA foram sancionados antes da promulgação da Constituição Brasileira, fica claro a falta de concordância entre as obrigações e responsabilidades propostas para cada instância política, criando lacunas e confusões que possibilitam o não-cumprimento dela e isentam os responsáveis, que acabam deixando a cargo de terceiros o controle e o direcionamento da atividade.

A ocupação desse território não foi precedida de estudos que poderiam prevenir os impactos negativos e até mesmo dimensionar a carga suportada por cada localidade e indicar os locais mais apropriados para a ocupação, criando municípios que têm sua vida urbana e econômica estruturadas em função quase que exclusiva das temporadas de férias. Porém, são poucos os municípios que conseguiram aparelhar a cidade para atender aos elevados índices de veranistas, apresentando muitas deficiências como a inexistência ou ineficiência de serviços básicos (coleta de esgoto, abastecimento de água e energia elétrica), escassez de espaços livres, insuficiência de hospitais e policiamento.

\section{Considerações Finais}

A iniciativa de construção de segundas residências privilegiou apenas àqueles que possuem condições financeiras de serem proprietários desse tipo de imóvel e que pouco contribuem para o desenvolvimento do local e 
de sua população. Nem mesmo a economia e as administrações municipais podem se considerar beneficiárias da iniciativa, pois a maioria dessas residências secundárias estão inseridas em áreas rurais aonde não há a cobrança do IPTU (Imposto Predial e Territorial Urbano). Em contrapartida, toda a infraestrutura turística acaba sendo construída pela administração pública.

A ocupação das margens é expressiva e tende a aumentar com o decorrer do tempo, exigindo uma maior atenção e real preocupação das autoridades competentes.
Não existem previsões sobre os impactos reais dessa nova forma de ocupação, e tampouco sobre como essas comunidades serão afetadas com a proliferação exacerbada desses subúrbios de veraneio. O que encontramos hoje são feiras e divulgações regionais que colaboram com isso, sem se preocupar com o futuro.

O que nos leva a crer que, sem um direcionamento e delimitação de formas de uso, a região tende a caminhar para um final semelhante às regiões litorâneas brasileiras do sul e sudeste: saturação total dos atrativos naturais.

\section{Referências Bibliográficas}

ASSIS, Lenilton F. Turismo de segunda residência: a expressão espacial do fenômeno e as possibilidades de análise geográfica. Revista Território. Rio de Janeiro: ano VII, $\mathrm{n}$. 11, 12 e 13. set/out, 2003. p 107-122.

BARROS, Nilson C. Crócia de: Manual de geografia do turismo: meio ambiente, cultura e paisagens. Recife: Universitária da UFPE, 1998.

BRASIL. Constituição da República Federativa do Brasil. Brasília: Senado Federal, 1998.

BRASIL. Lei no 4.771 , de 15 de setembro de 1965. Institui o novo Código Florestal Brasileiro. Diário Oficial da República Federativa do Brasil. Brasília, 1965.

Companhia Energética DE MINAS GERAIS (CEMIG). Institucional: Usinas da Cemig. Disponível em <http://www.cemig.com.br/ institucional>. Acesso em: 17 jun. 2006.

CRUZ, Rita de Cássia Ariza da. Introdução à geografia do turismo. São Paulo: Roca, 2001.

. Geografia do Turismo: de lugares a pseudo-lugares. São Paulo: Roca, 2007.

Políticas de turismo e (re)ordenamento de territórios no litoral do Nordeste do Brasil. Tese (Doutorado em Geografia) - Faculdade de Filosofia, Letras e Ciências Humanas, Universidade de São Paulo. São Paulo: 1999.
ESTAÇÕES FERROVIÁRIAS DO ESTADO DE SÃO PAULO. Cia. Mogiana de Estradas de Ferro (18881970). Disponível em: <http:// www.estacoesferroviarias.com.br/r/rifaina.html>. Acesso em: 20 ago. 2004.

Furnas Centrais Elétricas S.A. Disponível em: <http://www.furnas.com.br>. Acesso em: 17 jun. 2006.

INSTITUTO BRASILEIRO DE GEOGRAFIA E ESTATÍSTICAS (IBGE). Sinopse preliminar do censo demográfico 2000 - São Paulo e Minas Gerais. Disponível em: <http:// www.ibge.com.br>. Acesso em: 12 abr 2006.

. Sinopse preliminar do censo demográfico 1990 - São Paulo e Minas Gerais. Disponível em: <http://www.ibge.com.br>. Acesso em: $12 \mathrm{abr}$ 2006.

Sinopse preliminar do censo demográfico 2000 - São Paulo e Minas Gerais. Disponível em: <http://www.ibge.com.br>. Acesso em: $12 \mathrm{abr}$ 2006.

KNAFOU, Remy. Turismo e Território. Por uma abordagem científica do turismo. In: RODRIGUES, Adyr A. B. (org.). Turismo e Geografia: reflexões teóricas e enfoques regionais. São Paulo: HUCITEC, 1996, p.33-38.

MACEDO, Silvio Soares. Assentamentos Urbanos de Segunda Residência no Litoral: Destruição e 
Construção. In: Questões Ambientais Litorâneas: Um Seminário Interuniversitário (ANAIS). Universidade São Paulo, 1993. p. 4547.

Paisagem, modelos urbanísticos e as áreas habitacionais de primeira e segunda residência. In: Paisagem e Ambiente: ensaios. Faculdade de Arquitetura e Urbanismo - USP. São Paulo, 1997, p.133-202.

NICOLAS, Daniel Hiernaux. Elementos para un analisis sociogeográfico del turismo. In: RODRIGUES, Adyr A. B. (org.) Turismo e reflexões teóricas e enfoques regionais. São Paulo: HUCITEC, 1996. p. 39-54

QUEIROZ, Odaléia T.M.M.; SENA, Maria de Fátima A. Impactos ambientais e sócio-culturais do turismo de segunda residência: o caso de Ponta da Tulha, Ilhéus, BA. Bahia: Caderno
Virtual de Turismo, 2006. p.96-106. Disponível em: <http://www.ivt.coppe.ufrj.br>.

SÁNCHEZ, Joan-Eugeni. Espacio, economia y sociedade. Madri: Siglo Veintiuno, 1991.

SANTOS. Milton Santos. A natureza do Espaço. São Paulo: Editora da Universidade de São Paulo, 2. ed, 2004.

SEABRA, Odette C. de Lima. A muralha que cerca o mar: uma modalidade de uso do solo urbano. 122 f. Dissertação (Mestrado em Geografia) Faculdade de Filosofia, Letras e Ciências Humanas, Universidade de São Paulo. São Paulo: 1979.

TULIK, Olga. Residências Secundárias: presença, dimensão e expressividade do fenômeno no Estado de São Paulo. Tese (Livre-docência) Ciências Sociais Aplicadas, Universidade de São Paulo. São Paulo: 1995.

Trabalho enviado em outubro de 2009

Trabalho aceito em dezembro de 2009 